\title{
Mathematical modelling as basis for efficient enterprise management
}

\author{
Svetlana Kalmykova ${ }^{1, *}$, Alexander Krasnoshchekov ${ }^{1}$, and Petr Pustylnik ${ }^{2}$ \\ ${ }^{1}$ Peter the Great St. Petersburg Polytechnic University, 195251, St.Petersburg, Polytechnicheskaya, 29 , Russia \\ ${ }^{2}$ Herzen State Pedagogical University, St. Petersburg, Russia
}

\begin{abstract}
The choice of the most effective HR- management style at the enterprise is based on modeling various socio-economic situations. The article describes the formalization of the managing processes aimed at the interaction between the allocated management subsystems. The mathematical modelling tools are used to determine the time spent on recruiting personnel for key positions in the management hierarchy selection.
\end{abstract}

\section{Introduction}

The economic recession revealed explicitly the problem of Russian of industrial enterprises management low efficiency in real time, and that revelation led to the relevance of the theme of this article.

The crisis in the Russian economy started developing since 2008. This situation can be illustrated by the indexes of electricity and steel production in Russia dynamics (see. Fig. 1) [1, p.102]. Line "1" is the dynamics of electricity (MWh); line " 2 " is the dynamics of steel production (millions of tons).

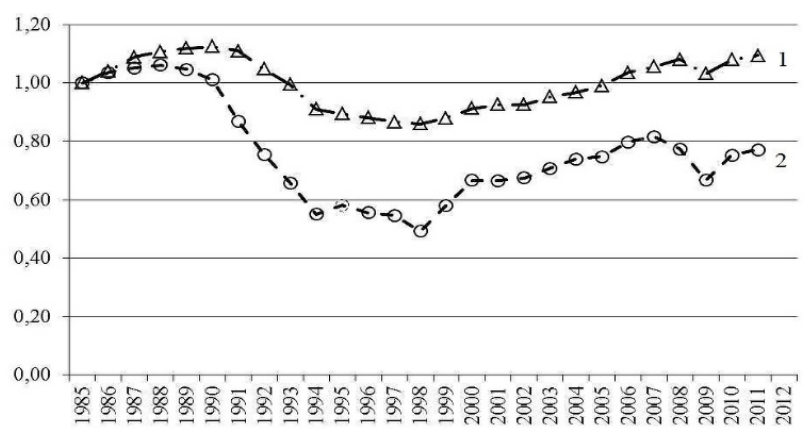

Fig. 1. Dynamics of production indexes $(1985=1)$.

In the article $[2$, p.20] the author attempted to determine the role of the various industrial enterprise management features (see. Fig. 2) based on the assumption that the governance (the management) of the economic system is the top of the management pyramid. With this approach, marketing, controlling and logistics are part of industrial management.

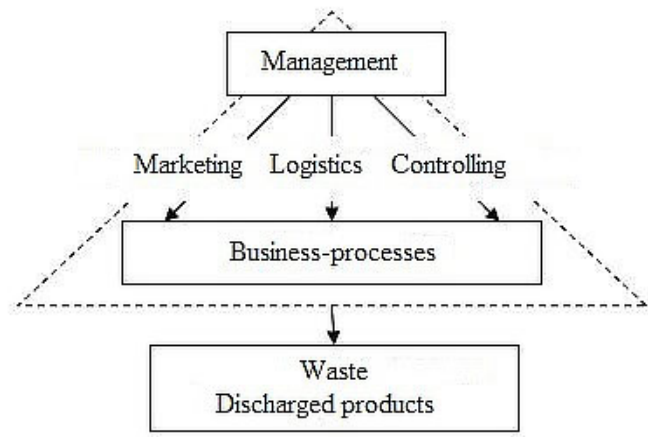

Fig. 2. Enterprise management pyramid.

To describe the process of industrial production with the help of logistics terms, it is necessary to take as a basis the movement of material flow: resource market $(0) \rightarrow$ supply (1) $\rightarrow$ production (2) $\rightarrow$ sale (3) $\rightarrow$ goods market (4).

\section{Formalize the industrial enterprise management process}

The chart will help us formalize the industrial enterprise management process (see. Fig. 3)

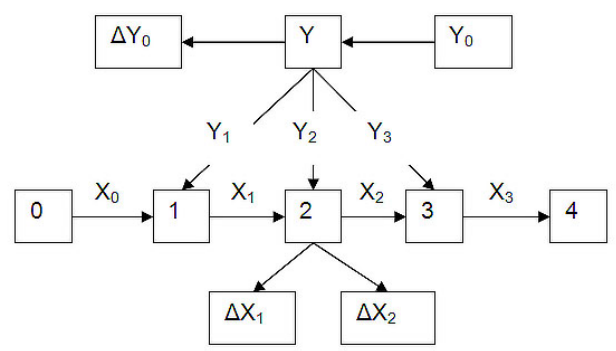

Fig. 3. The formalized enterprise management chart.

\footnotetext{
Corresponding author: kalmykovas@mail.ru
} 
Symbols shown on the simplified scheme of industrial enterprise management:

X0 - the movement of materials and semi-finished products from the resource market (from the suppliers) to the warehouse of the enterprise;

$\mathrm{X} 1$ - the movement of materials and semi-finished products from the company's warehouse to the production areas;

$\mathrm{X} 2$ - the movement of manufactured products to the site storage of finished products;

X3 - the movement of manufactured products from the area of site storage of finished products to the goods market (to the consumer);

$\Delta \mathrm{X} 1$ - production waste;

$\Delta \mathrm{X} 2$ - discarded products;

$\mathrm{Y} 0$ - the request from a potential customer (the demand for the product on the goods market);

$\mathrm{Y}$ - the administrative decision taken at top management level;

Y1 - the command for the supply service to purchase the materials, semi-finished products, etc.

Y2 - the command for the production areas about the number of required products and the timing of production;

Y3 - the command for the sales service to ship the finished products to the customer;

$\Delta Y 0$ - the reject to manufacture the requested products.

The balance of the material flow is described with the equation:

$$
X_{0}=X_{3}+\Delta X_{1}+\Delta X_{2}
$$

The task of production management can be considered fulfilled if the shown condition is followed:

$$
X_{3}=Y_{0}-\Delta Y_{0}
$$

The request of the customer ( $\mathrm{Y} 0)$ generates at least three control actions (Y1, Y2, Y3) to perform core business functions: supply, production and sales.

Control actions within production management in aggregated form can be represented by the equation:

$$
Y=\sum_{i=1}^{3} Y_{i}\left(X_{i}\right)
$$

If we consider the process of industrial production from the management point of view, depending on the purpose of the research as a basis for reasoning, we choose one of the links in the chain: the forecast $\rightarrow$ the decision $\rightarrow$ the production of management commands $\rightarrow$ the command execution $\rightarrow$ the comparison the result with the forecast $\rightarrow$ the grounding of a new forecast $\rightarrow$ etc.

The processes of globalization change the formalization of development forecasts for the whole industries and for individual companies under the influence of economic crises, which transform the model of industrial enterprises management.

The development of enterprise management model (an approach of Ansoff) was carried out in three stages [3, s.399-413]:

1950-s. - The development of methods to adapt to the changing situation on the market;

1970-s. - The method of management according to the circumstances;

1980-s. - Crisis management.

In 1966, the J. Galbraith (1908-2006) warned: "In the initial stage of development of the corporation, particularly in 1930, the experts concerned that the people who control the company, can make it an instrument of their personal enrichment ... Theft of unprecedented proportions threats the society "[4 s.181182]. Unfortunately, in Russia this prediction come true at the turn of XX-XXI centuries with the establishment of capitalistic relations and the privatization of industrial enterprises.

Improvement of production management methods involves consideration of certain factors that are uniquely connected with each other and affect the functioning of the enterprise both directly and indirectly.

The production system can identify the main subsystems, each of which can be established as an isolated object of control:

1. Supply management (definition of purchase prices, their minimization in the procurement of quality raw materials).

2. Production management (definition the percentage of discarded products and waste in order to maximize the use of material resources).

3. Sales management (modeling ways to minimize losses during storage of goods (warehouses); model timely goods delivery).

Management of industrial enterprise subsystems is based on the sales forecast in the next period, formed on the basis of statistical data. It can be assumed that the selection an effective personnel management style we should take into account the short economic cycles (Mitchell cycles) which were obtained in the analysis of statistical data for the period 1878-1922 gg. [5]. In Russian Mitchell cycles can be observed in the graph dynamics steel melting production indices (it was shown in Fig. 1).

Modeling the interaction between selected subsystems is possible with the use of game-theoretic models, which provide a basis for decision making in the company's development strategy. In the XXI century strategic development plan of the industrial enterprise should include activities related to the introduction of the concept of "lean production" (LP).

LP concept began to take shape through the works of FW Taylor (1856-1915), who published by the 1911 the principles of scientific management [6], and H. Ford (1863-1947), who introduced the pipeline division of labor in 1913,. [7] The modern version of the LP concept is based on the development of Tahiti It (1948), which in its final form in 1973, in Japan was called «Toyota 
Production System» (TPS), and «Lean Production System » LPS in 2000, in the United States [8].

As a result of production management state research in Russia it was concluded, that using the methods of LP "highest estimate had a system of workplace organization $5 \mathrm{~S}$ », and on down the rated: Kaizen, the TPM, Kanban, J-in-T [9, p. 22].

Currently there is no single answer to the question, how to organize the industrial enterprises management so that the motivation of the staff is not reduced for an extended period.

In a research on human resource management techniques [10, s.155-161], the role of the management team is highlighted, but it should be emphasized that the action of each team is led by the leader who uses a particular style of management.

For various industrial enterprise management styles we will consider:

0 - as the statement of the problem to the subordinates and its perform without interference from the first person;

1 - as the setting an objectives to the subordinates followed by detailed first person control of the all the action.

We form a matrix $A=\left(a_{i j}\right)$ of control actions possible combinations, where :

$$
i=1,2,3 ; j=1,2, \ldots, 7
$$

$$
A=\left(\begin{array}{lllllll}
0 & 1 & 0 & 0 & 1 & 0 & 1 \\
0 & 0 & 1 & 0 & 1 & 1 & 1 \\
0 & 0 & 0 & 1 & 0 & 1 & 1
\end{array}\right)
$$

The lines correspond to the three services: supply, production and sales, and the columns corresponds to the combination of management styles.

Each service has its own criteria for evaluating the efficiency of performance ${ }^{\wedge}$

- Supply - the acquisition of high-quality raw materials and semi-finished products for the least possible cost in the required amount before the start an order in the production;

- Production - manufacturing products according to the working schedule without discharged products from the waste volume not exceeding technological norms;

- Sales - the shipment of finished products, in accordance with a complete set of delivery schedule without disruptions.

Since most understandable for Russian managers of the lean manufacturing techniques is the $5 \mathrm{~S}$ system, we summarize the experience of its ordinary version application in an industrial enterprise.

The stage of implementation of the principles of $5 \mathrm{~S}$ system ("sort", "maintenance of order", "keeping clean," "standardization", "improvement") requires management style " 1 " as the staff perceives the need for an inventory of all items in the workplace as an extra work done without payment.

At the usual use it is better to use the style of " 0 ", as in the team of each business unit an informal leader is detected. This leader initiates the effective application of the $5 \mathrm{~S}$ system principles.

Possible combinations of control actions on the personnel of the industrial enterprise structural divisions are shown in Figure 4. Letter "D" drown on the chart means "decision" (manager's decision).

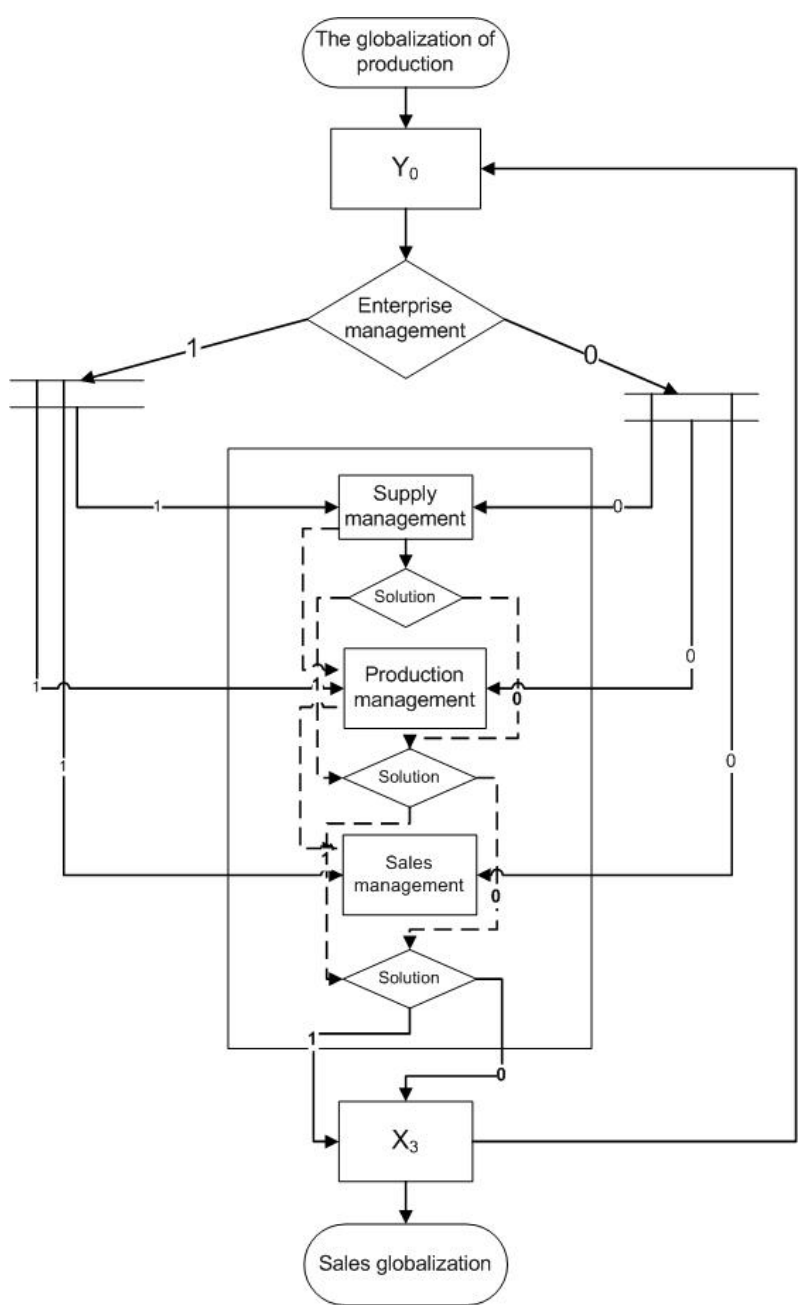

Fig. 4. Possible combinations of control actions.

One of the significant factors affecting the generation of management teams, is the globalization of production and sales, which initiates crises: the crises of underproduction and overproduction crises.

The ideal situation is a complete coincidence of supply and demand, the time when all the products are made entirely for the end-user. This situation is considered in most of mathematical models, which describe the motion of the material flow in the production system.

In general, the objective function for the solving task for an industrial corporation has the following form [11]:

$$
\begin{gathered}
O P T(I)=\sum_{i=1}^{n} l\left(d_{i}\right), \ldots, d_{i} \in D, \ldots n=|D| \\
D=\left\{d / d \in D^{s 1}, \ldots, D^{s p} ; l(d)^{s 1}=\ldots=l(d)^{s p} ; k(d)^{s 1}=\ldots=k(d)^{s p}\right\}
\end{gathered}
$$

Where:

$D^{s}$ is a plurality of structural units of the corresponding activities;

$S$ is one of the analyzed activities;

$p$ is one of the industrial enterprises of the corporation; 
$k(d)^{s i} ; l(d)^{s i}$ are the parameters of control actions on structural units on each i-th iteration control options;

$D$ is the set of all structural units of the industrial corporation;

$I$ is a task for which the best solution is sought.

The objective function in the absence of constraints determines the maximum possible theoretical estimate of the optimal solution $O P T_{\text {theor }}(I)$, representing the amount of control actions on the common structural unit, for which a non-empty intersection of all the group companies exists.

Possible extremes different functions: maximization of the enterprise owner profits; minimization of discharged products amount; minimization of the theft amount in the workplace; maximization of the least paid categories of workers' salaries; minimization of topmanagement wages, etc.

Going through the possible combinations $k(d)^{s i} ; l(d)^{s i}$ of control parameters effects on the structural divisions of the corporation can get different effects of economic activity ( $E$ ) for each combination of $\mathrm{i}$ :

$$
E(Y)=\sum_{i=1}^{3} A_{i} \cdot k(d)^{i} \cdot l(d)^{i}
$$

Detailed top-manager control of the task execution is accompanied by a time-consuming because of continuous action coordination. This control also deprives the subordinate desire to take the initiative. With the tight control theft at the company is only possible with the permission of the head.

Giving carte blanche subordinate reduces the time required to solve tactical problems, frees up time for the formulation of strategic objectives, as well as allows revealing the creative potential. However, in this case, the theft caused by the personal initiative of employees is possible.

While managing microenterprises detailed control is inevitable, as the owner of the company (if it is not firm for one-day) typically performs several functions: recruitment, personnel management, the acquisition of the necessary manufacturing process technology, regulation of labor, accretion of premiums and imposition of penalties, manufactured products quality assessment, customer search, preparation of the contract, search for resources and suppliers etc. The only feature that is rarely performed by managers of microenterprises is accounting.

While managing small business owner of the company (if it is not one-day firm), combines different positions: CEO, managing director, chief engineer, director of personnel, and director of quality. This helps to gain a detailed control of all business processes. Some functions are delegated to the hired personnel. Usually it is accounting, process management, legal and patent support.
While managing medium and large enterprises enterprise owner sometimes keeps his position as "CEO", and is always in control financial flows. For key positions recruitment of each management level sorting options combining management styles and selecting managers with the necessary set of qualities are needed.

\section{Conclusion}

Any industrial enterprise management is the process of interaction of various types of administrative activity, with both dynamic and static manifestation. It is aimed at the adaptation of economic activities to the continuously changing economic conditions.

Changes in the economic situation (crisis or stability) suggest a change of management style that is accompanied by a change in top-management team of the company.

Mathematical modeling of socio-economic situations reduces the time spent on the choice of industrial enterprise and sub-systems management style. This approach simplifies the work of personnel recruitment for key positions in the management hierarchy.

\section{References}

1. P.N. Pustyl'nik, Deichite Extraction, 5, 101-104 (2013)

2. P.N. Pustyl'nik, Scientific and Technical Sheets SPbSPU, 4(52), 17-21 (2007)

3. I. Ansoff, New corporate strategy (Piter Kom, St. Petersburg, 1999)

4. Dzh. Gjelbrejt, The New Industrial Society (Terra Fantastica, St. Petersburg, 2004)

5. C. Mitchell Wesley, Business Cycles: The Problem and Setting (National bureau of Economic Research, New York, 1927)

6. Tejlor Frederik Uinslou, Principles of Scientific Management (Control, Moscow, 1991)

7. Genri Ford, My Life (Finance and economics, Moscow, 1989)

8. Majkl L. Dzhordzh, Lean Manufacturing + Sigma. Combining the quality of shanti sigma with the speed of lean production (Al'pina Biznes Buks, Moscow, 2005)

9. Third Charnov Readings: a collection of abstracts. Materials of the III International Scientific and Practical Conference on the Organization of Production, 8-22 (2013)

10. M.V. Lopatin, S.V. Tevlina, Scientific and Technical Vedomosti SPbSPU, 6(68) (2008)

11. S.V. Kalmykova, A.S. Sokolicyn, Scientific and Technical Bulletins of SPbSPU, 6(162), 185-190 (2012 